\title{
Leadership strategies: re-conceptualising strategy for educational leadership
}

\author{
Scott Eacott
}

School of Education, The University of Newcastle, Callaghan, NSW, Australia

Dr Scott Eacott

School of Education

The University of Newcastle

Callaghan NSW AUSTRALIA 2308

Ph: $\quad+61(0) 249217805$

Fax: $\quad+61(0) 249217887$

Email: Scott.Eacott@newcastle.edu.au

Web: http://newcastle-au.academia.edu/ScottEacott

(Received 03 March 2010)

\begin{abstract}
Strategy is a much debated concept in the field of educational leadership. This paper draws on a variety of data from a larger research programme focused on reconceptualising strategy in the specific context of school leadership. Rather than offering a definitive voice, this paper lays the foundations for further inquiry on the topic through a greater 'practice' orientation. Drawing on policy analysis, questionnaire and interview data, this paper proposes an alternate theoretical frame for strategy in educational leadership that takes into account the various social, political, historical and cultural forces which seek to influence the behaviour of both leaders and schools.
\end{abstract}

Keywords: word; strategy; leadership; strategies; Bourdieu

\section{Introduction}

Ironically, within the field of educational leadership, the very concept of 'strategy' is well concealed by its hype, and lies in stark contrast with the uncritical adoption of (new) ideas of leadership, management and administrative thought (Bell, 2002), organisational design (Dimmock \& Walker, 2004), and the techniques of evidence based decision making (English, 2003) from the corporate sector. Therefore, the use of strategic leadership as a descriptive ‘label’ (Gunter, 2004) is highly problematic (Bell, 2002), as some (see Bush, 2007; Gunter, 2004) have questioned as to whether the change in nomenclature from administration to management and then leadership is due to a shift in activities, responsibilities and accountabilities or mere semantics. The 
strategic task of the educational leader is to take up the challenge of complex historical, cultural, social, and political influences, uncertain economic conditions, ever advancing technologies and increasingly diverse student populations. As educational leadership scholars and practitioners, our strategic challenge is to figure out what our work as leaders should be in new times.

The argument of this paper is theoretically informed by the work of the French sociologist Pierre Bourdieu. It builds on Lingard and Christie (2003), Lingard et al. (2003), and a continued research programme by the author, to argue for a more sophisticated conceptualisation of strategic educational leadership as a social practice. Viewing strategic leadership as a complex social activity moves scholarship and understanding beyond the superficial measurement of what is directly observable to a thick description of practice. Such a shift privileges the practice of leadership over any specific list of traits, behaviours or nominal titles. If the goal of educational leadership scholarship is to offer potentially powerful explanatory frameworks which provide insights into how school leaders act, then such a shift is required. The unique contribution of this work is the heightened attention to Bourdieu's conceptualisation of strategies as the 'leadership habitus' (Lingard et al., 2003) enacted and highlighting the importance of examining how cultural, economic, historical and political forces within a given context play out in the leadership of schools.

\section{Methodology}

This paper derives from a larger research programme seeking to reconceptualise the strategic role of school leaders. The underlying assumption of this research programme is that to understand strategic leadership it is important to engage with issues of power, reality construction, symbolic order, actor networks and language 
games. The importance of the topic of strategy in educational leadership centres on the centrality of education within contemporary society and not just for the purpose of producing economically productive citizens, rather, citizens who are capable of challenging existing thought and making the world a better place. The work is theoretically informed by the French sociologist Pierre Bourdieu. The argument of this paper works with Lingard and Christie (2003) and Lingard, Hayes, Mills and Christie (2003) by seeking to de-romanticise educational leadership and explicitly link leadership actions to the social space in which they occur. Using Bourdieu’s conceptualisation of strategies as not conscious, individual rational choice, but appropriate actions taken without conscious reflection, strategy or the 'feel for the game' (Lamaison \& Bourdieu, 1986), is theorised as moves in the game that are based on mastery of its logic, acquired through experience. Strategy is therefore a social practice and not a specific behavior, trait or document. The discussion section of this paper draws on a variety of data collection methods (including interviews with principals, analysis of policy documents from systemic authorities and questionnaires) to provide a synoptic view of where the research programme is currently positioned.

\section{Findings}

The empirical work from which this paper derives was undertaken in the public school system of New South Wales, Australia between 2005 and 2008. Data collection techniques include policy analysis, interviews with practising principals and questionnaires. Due to the brevity of a journal article some background information on the development and pilot of instruments is omitted. For those wishing to pursue this information see Eacott (2009). 


\title{
The context of practice
}

Dimmock and Walker (2004) argue that strategy has become synonymous with planning in the school policy context. In a 2005 memorandum to school principals, regional directors, school education directors and state officers, Trevor Fletcher, the Deputy Director of Schools wrote:

\begin{abstract}
We have come to the view that school planning is best presented as both a continuous process of quality improvement and an iterative process with a three year planning horizon.

The aim is to provide a three year plan updated annually. Led by the principal and with increased input from teachers, parents and students, the school community, following careful consideration of student outcomes and program performance, can set long term goals and shorter term targets. Linked to annual school reports, the publicly available school plan provides a framework for resource allocation, professional learning, system support and performance monitoring and reporting.
\end{abstract}

Note the explicit endorsement of Deming’s (1982) 'quality improvement', which is arguably an appropriation of Taylor’s (1911) Scientific Management. In a document supporting the memorandum, a model for school planning is provided. It is described as a continuous, iterative process best understood as cyclical, developmental and adaptive, and directed at improved teaching and learning. However, it presents as a linear decision making and planning model, conforming to Deming's quality systems management (e.g. plan, do, check and report). The delivery of such a model by the system to schools endorses the model as the preferred, giving it legitimacy and serving to establish the model as the norm. While not explicitly stating so, the fact that it is present indicates that this is what supervisors (in the form of school education directors, the Australian equivalent to superintendents) will be looking for. Covertly, if not explicitly, the system has invoked and set the standard from which school plans (the written articulation of the school's strategic direction) will be evaluated. The system has used its access to all schools to effectively legitimise its model, normalise the behaviour of principals and shape the ontological 
reality of what is strategy in schools. A similar phenomenon occurs in the UK (Cuckle \& Broadhead, 2003) where school development plans became part of school leadership following the Education Reform Act 1988.

Additionally, the push toward evidence based decisions is directly raised in the 'careful consideration of student outcomes and program performance'. In principle, the role of student outcomes and program performance in strategic decisions makes good sense. However, the reporting of student outcomes and program performance in annual school reports is frequently limited to state-wide testing regimes. In such cases, English (2003) reminds us that the decisions regarding what is important and privileged are already made by the choice of evidence collected. State targets for literacy and numeracy are highly political and reduce the complex path towards knowledge creation to a number (e.g. $75 \%$ of students in year three will achieve state benchmarks for literacy and numeracy). Meeting such targets become the criteria for the assessment of school performance (as the current debate surrounding the establishment of league tables in Australia demonstrates). During an interview a principal noted:

Being effective is what it is all about. Defining effective requires you to go back to your goals and targets and seeing how you are going. You need hard data to support your case. Principal 36

Despite the rhetoric of participation and empowerment at the school level, the Trojan horse from which strategic planning is sold to schools and the wider community, the state through systemic authorities continue to set the targets which trickle down, or in some cases 'are forced down', to the school level and in doing so define what is an 'effective school' (see Ball, 1997). That is, through the legitimising of a particular model - defining what strategy in schools is - and the normalising 
effects of what makes a good school - by defining the criteria for evaluation - the dominant group has shaped the ontological reality which it is focused on. As a principal noted:

... while the powers that be [systemic authorities] tell us that they are trying to devolve power and it is going to no longer be a top-down model, in actuality, we have become far more accountable for what we are doing to those above us in the system.

Principal 18

Furthermore, principals are embedded within these discursive mechanisms which seek to normalise behaviour. As schools and consequently principals are being evaluated on the meeting of targets and value added data, there is a persuasive rationale for school leaders to structure their leadership and management around adding value to school performance data. Simply put, if principal performance is being evaluated on the basis of quantifiable data from standardised tests (currently literacy and numeracy only) and the system is delivering a linear rational model of decision making and goal setting, the policy context is shaping the way principals conceptualise their work.

I think that what we have become in many ways is a group of clones. We [principals] are not risk takers and I think we need to stick our head out a bit and take some risks. Principal 10

\section{The behaviour of leaders}

Two methods were used to investigate the strategic behaviours of principals. The first was a questionnaire based study on a convenience sample of 76 principals. The second method was a series of interviews with a sub-sample of 36 principals. 
Working with a conceptual framework developed from a comprehensive literature analysis of both conceptual and empirical work on strategy in education (see Eacott, 2009), a questionnaire (designed specifically for this study) was used to identify the perceived current performance of the strategic role of principals. The Strategic Leadership Questionnaire (SLQ) consists of 36 items divided into five scales (consistent with the conceptual framework of the study), each consisting of six to eight items. To overcome issues relating to self-reporting, participating principals were asked to distribute 12 questionnaires to raters within the school community. Raters come from four categories, organisationally above the principals (e.g. school education directors), at the same level as the principal (e.g. other principals), organizationally below the principal (e.g. deputy principals, assistant principals, teachers) and other (e.g. administrative staff, parents, school council members). This enabled multiple perspectives on the principal's enactment of their strategic role. Participants were asked to rate the level of performance of the principal (or in the case of the principal, themselves) on a six point Likert scale ranging from 1 'strongly disagree' to 6 'strongly agree'. The five scales of the SLQ were: i) Envisioning designed to measure the principal's behaviour towards the creation of a desired future position for the school; ii) Engaging - focused on the active involvement of a wide range of participants in conversations, discussions and decisions regarding the strategic direction of the school; iii) Articulating - catering for the oral, written and structural articulation of strategy; iv) Implementing - concerned with the translation of the school's strategic direction into action and particularly the alignment and timing of actions; and v) Monitoring - focused on the processes of continuous, systematic monitoring of actions through in-depth evaluation. 
Table 1 displays the scale and overall results for the questionnaire. In recognition of the negative skew and relatively high kurtosis of the data, it is concluded that participants in the study frequently exhibit strategic leadership and management behaviours as described in the literature. Means ranging from 4.71 to 5.07 reflect a trend between slightly agree and agree (even if the median was used based on the skew and kurtosis, the result would still fall within the same range). However, such results are not surprising (Davies \& Davies, 2006). If, as highlighted previously, the systemic authority has shaped the ontological reality through the distribution of policy and the endorsed model, the normalising effect of such is that most principals most of the time would exhibit desired behaviours.

Table 1. Descriptive statistics from questionnaire

\begin{tabular}{|c|c|c|c|c|c|c|c|c|}
\hline \multirow[b]{2}{*}{ Scale } & \multirow[b]{2}{*}{$N$} & \multirow[b]{2}{*}{$\bar{x}$} & \multirow[b]{2}{*}{$\sigma$} & \multicolumn{2}{|c|}{ Skewness } & \multicolumn{2}{|c|}{ Kurtosis } & \multirow[b]{2}{*}{ Median } \\
\hline & & & & Static & S.E. & Static & S.E. & \\
\hline Envisioning & 76 & 4.71 & .57 & -.92 & .28 & 1.92 & .55 & 4.82 \\
\hline Engaging & 76 & 5.07 & .55 & -.99 & .28 & 1.10 & .55 & 5.19 \\
\hline Articulating & 76 & 4.88 & .53 & -.69 & .28 & 1.19 & .55 & 4.90 \\
\hline Implementing & 76 & 4.97 & .48 & -.56 & .28 & .40 & .55 & 5.00 \\
\hline Monitoring & 76 & 4.86 & .50 & -.46 & .28 & .43 & .55 & 4.90 \\
\hline Overall & 76 & 4.91 & .48 & -.70 & .28 & 1.07 & .55 & 4.95 \\
\hline
\end{tabular}

To add an extra layer to the results, a sub-sample of the principals were interviewed to gain deeper insights into how principals thought they acted strategically. Following transcription of the interviews, a lexicographic analysis of the responses was conducted, through which the 'distinctive vocabulary' of the strategic role of the school principal was identified. This process is a modified version of conventional coding in grounded theory (see Strauss \& Corbin, 1998). The process is a form of content analysis, where the goal is to conceptualise the core features of the 
strategic role from within the extensive text through the identification of distinctive words and phrases. The core features of the role serve as the building blocks for a theoretical positioning of the inductive definition. This multi-step process frames the following definition of the strategic role of the primary principal, as imputed from the distinctive lexicon of the text: 'The strategic role of the public primary school principal deals with (a) advancing the school's purpose; (b) by balancing the demands of others; (c) synthesizing and providing direction; and (d) through leadership behaviours.' It is acknowledged that this definition is not elegantly worded or graceful in syntax. Rather, it represents the best effort to integrate the four dimensions into sentence form. Adhering to this method of induction allows the definition to differ fundamentally from others, because it represents the way principals talk about the role, rather then asking questions derived from a pre-conceived model.

In order to understand strategy leadership as described by principals requires an acceptance of ambiguity and complexity. It highlights the importance of examining how cultural, social, historical and political forces within a given context play out. It is important to identify and acknowledge that each individual school is situated in the social space that is education within any given region/state and that much of the individual identity of a school comes from the set of relationships it has with other schools and wider society. The purpose of schooling is a contested terrain, and balancing the needs of others requires principals to have an understanding of how different groups conceptualise 'the school' and the purpose of schooling. Such an empirical pluralist stance acknowledges difference in the conceptualisation of schooling and takes up the challenge of ongoing social struggles. Synthesising and providing direction, the most common focus of strategy research, remains but one dimension of strategic leadership, not the entirety. As Bourdieu (1988) argues, 
documents which frequently start with official statistics (a clear link back to the policy context) are objectified products which institutions continually perform. A narrow and sociologically naïve focus on such products and performances fails to engage with the underlying power struggles that shape and define such documents and performances. While as a domain of inquiry educational leadership continues down the path of distributed leadership (which has the underlying assumption that leadership is a commodity which can be traded like stocks), principals spoke of the strategic role as requiring leadership to, with and from others. As with other dimensions of the implicit definition, this again highlights the constant, but not always directly accessible, power struggles between actors in the leadership and management of educational institutions.

\section{Leader's thinking}

In recognition that principals' thinking about their role is not directly accessible, as part of the semi-structured interview, principals were asked to provide an analogy which best describes their experience of the role. These analogies give narrative access to knowledge that the principals might not have been able to express in terms of the conventional language of the field and is consistent with the Bourdieuian notion that the logic of practice is not directly accessible. The two most common analogies involved sailing (getting to a destination and organising people) and sporting teams (participation and win/lose as a team). Both analogies reflect a means-end rationality, with the latter conforming to contemporary discourse focused on distributed leadership. However numerous analogies give insights into the role that are beyond common portrayals in the literature. These analogies begin to expose the relational and dynamic elements of the role. Practice is not static and following Bourdieu, 
effective performance requires an understanding of the logic of the game. A specific example is:

\begin{abstract}
It [the strategic role] is probably like a very good sexual relationship long term, because it is long term and its where people are equal and its not always easy and its not always what you want and what you feel like, but its something that can be really exciting, you want to work on it, but if you're not involved in it, you're not going to enjoy it. But it can't be something where someone else can do all the hard work for you and you go hey yeah, this is great, because that doesn't work, it's that team work and that people are engaged together and being a part of something. It can be sort of full one and other times have nice sort of gentle lulls that you enjoy.

Principal 36
\end{abstract}

Throughout the analogy there is an underlying assumption of the need to understand the social space. This involves the enactment of unconscious assumptions, a working knowledge of the value placed on those behaviours by your partner and the power relations within the relationship. The past experiences of the two actors have established a history of acceptable behaviours. These norms of behaviour serve as the boundaries of the game. While there are an infinite number of possible moves within the relationship, past experiences have created a 'relationship culture'. This is not to suggest a rigid set of rules or procedures for the game, as strategy requires innovation, rather, it (the relationship culture) exists as an unconscious guide for actions. This unconscious guide is developed through sustained interactions between the actors and is constantly evolving. Comments such as 'where people are equal', 'it can’t be something where someone else can do all the hard work for you', and 'that people are engaged together' expose the invisible power relations. While at any given moment it may appear that one person is dominant, overall (as this analogy focuses on a macrolevel of the relationship rather than a micro-level analysis of individual behaviours) both parties are equal in the development of the relationship.

The reference to 'long term' moves the notion of strategy beyond the meansend usually applied to strategy. In doing so, any snapshot of strategy in practice is 
similar to trying to capture someone's life story in a single photograph. Comments such as 'it is not always easy', or 'what you want or feel like', and 'it can be sort of full on and other times have nice sort of gentle lulls' highlight that any moment in time during a long term relationship is the result of historical and future struggles which cannot be directly accessed in that moment. The individual significance of any given event or action is but one element on an ongoing continuum of historical events and actions and future events and actions. A single snapshot is an unreliable predictor for future success due to its ahistorical assumptions. Even if a relationship was to end, the history that each individual actor takes with them continues that history. This experience forms the unconscious behaviours of the future.

The normative nature of the field's literature provides many lists of leadership behaviours and traits. These lists and neat frameworks seek to provide a form of codified rules or explicit norms for practice. However, in reality, such as demonstrated by the above analogy, things are much more complicated and the infinite possibilities of actions cannot be captured in tables, models, diagrams or neatly packaged explanations of adjectival leadership. The good long term sexual partner, just as the good player or actor, has a natural sense of the game. Bourdieu notes:

The good player, who is at it were the embodiment of the game, is continually doing what needs to be done, what the game demands and requires. This presupposes a constant invention, an improvisation that is absolutely necessary in order for one to adapt to situations that are infinitely varied. This cannot be achieved by mechanical obedience to explicit, codified rules (Lamaison \& Bourdieu, 1986, p. 113). 


\section{Discussion}

For those who have utilised Bourdieu in the field of educational leadership, his concepts of capital (cultural, social, intellectual and symbolic), habitus, fields and strategies, have provided a lens through which to investigate the individual possibilities and contextual constraints within the work of educational leaders (Lingard \& Christie, 2003). A central aim of Bourdieu's sociology is the attempt to remove the dichotomy between the individual and society, in doing so, his theoretical insights and understanding make visible the indirectly accessible features of practice.

Bourdieu's writing on education argue that school autonomy is a deceptive device that helps to legitimise the domination of the state. In Bourdieu's (1998) view, bureaucracies such as education departments and governments are highly structured and resistant to change. As a powerful and relatively autonomous body, the bureaucratic institution embodies a specific habitus and logic of practice in its agents. As a result, agents, in this case the school leader, eventually come to act on behalf of 'the system' rather than public good or the interests of students. During an interview a principal noted:

\footnotetext{
I am a member of the Department of Education and Training. If they tell me this is going to happen, then that is what is going to happen. I might not agree with it, but I cannot stand up in the middle of the road and express my dissent. I do not feel that I can ignore or reject what my employer tells me to do.

Principal 31
}

Further, Bourdieu argues that the 'glorification of profit, productivity and competitiveness undermine the professional disinterest which is often found in people who enter the public service, especially street level bureaucrats’ (Lingard, Rawolle, \& Taylor, 2005, p. 773). This ‘performative’ (Ball, 2003) nature of school leadership is embedded in contemporary society. Ranson (2003) argues that methods of public accountability have been strengthened to the point where they are no longer 
components within a system, but the system itself. Strategic leadership and management, as presented in policy, is a technique used by dominant social groups, that is systemic and political authorities or the field of education policy, to expand the performative control over school leaders. In doing so, strategy, conceptualised as challenging the status quo, innovating on existing practice and leading the field is lost in conformity to the will of other dominant groups and contributing to social reproduction.

Further entrenching the performative nature of school leadership is the current professional standards movement sweeping the globe. Professional standards which seek to break leadership up and measure its parts go against the logic of accepting leadership as a complexity social activity. Such standards do little more than impose a model/expectation of what is 'effective leadership' and seek to normalise the behaviour of school leaders. This ongoing power struggle is the enactment of a larger struggle between the field of education policy and the field of education. As the field of education policy is primarily concerned with practices within schools, yet remains outside or above schools, it facilitates the indirectly accessible forces of such power struggles to remain hidden during most studies. Too often, educational leadership research is conducted in quick, insufficiently theoretically grounded inquiry. There is a tendency to view local knowledge as an add-on and not engage in analysis of how the macro- and micro-level interplay between fields play out in practice. The absence of thorough knowledge of local contexts, that is understanding the capital that is utilised in any given context, is 'one of the dangers of short term projects, which rarely allow one to get their hands dirty digging through layers of meaning at the micro-level because such excavation takes time’ (Vavrus \& Bartlett, 2006, p. 98). As 
such, much of the work in the field of educational leadership is sociologically naïve and the notion of practice is left under-developed.

Short term projects fail to adequately unpack the interplay between the macrolevel power plays and the micro-level moves of players due to a bias towards the remarkable. For example, a researcher asks a respondent to:

bring to the state of explicitness, for the purpose of transmission, the unconscious schemes of his practice. Just as the teaching of tennis, the violin, chess, dancing, or boxing breaks down into individual positions, steps, or moves, practices which integrate artificially isolated elementary units of behaviour into the unity of an organized activity, so the informant's discourse, in which he strives to give himself the appearance of symbolic mastery of his practice, tends to draw attention to the most remarkable "moves", ... rather than to the principles from which these moves and all equally possible moves can be generated and which, belonging to the universe of the undisputed, most often remain in their implicit state (Bourdieu, 1977, p. 19).

A particular limiting factor in such inquiry is that the informant produces a discourse that is bias towards the most remarkable moves and also one of familiarity. Through the immersion of familiarity, the school leader leaves unsaid all that he or she believes goes without saying. However, it is this junction, where the conscious and unconscious overlap that the 'feel for the game' or strategy exists. By omitting what are perceived to be the less remarkable moves, essentially where the decisions are made to pursue what are to become the remarkable moves, leaders, and implicitly researchers, are constraining what can be extracted about the phenomenon of leadership.

Working with the empirical findings previously reported, so far in this section issues underlying the practice of strategic leadership in schools has been discussed. The attention now turns to setting out an alternate theoretical conceptualisation of strategic leadership. Five dimensions make up what is labelled 'strategic leadership', the cultural, social, political, historical and future space. 
Understanding the cultural, social and political space of leadership practice involves the leader demonstrating an understanding that the context of their practice is constructed and not fixed. Therefore, to understand the context in which they work, leaders must have an understanding of the collective unconscious (or cultural space where the culture refers to the field of education) assumptions of their work, the value placed on their work by a diverse range of societal forces (e.g. social space where the value is aligned with various forms of capital) and power relations (e.g. the political space representing the continuous power struggles within and between fields). This requires school leaders to use and interpret multiple sources of information and evaluate alternate points of view, a leadership habitus. Bourdieu (1989) notes that habitus implies a sense of one's place but also a sense of the place of others. However, a key distinction that is relevant is between 'acting and having a reason and acting because of that reason (Fay, 1994, p. 92). While having a reason and being able to rationally justify a course of action is fine, unless the having of this reason was the cause of the actions, the reason does not explain the act. This is an example of what Marx referred to as mistaking the things of logic for the logic of things.

In addition to these features, any action is embedded in a temporal sequence. Therefore it is vital to acknowledge that the interactions that a researcher, or anybody for that matter, observes at any given time are the product of historical developments and struggles that require analysis. Strategy is always a work in progress. The determination of strategies is a piece of social construction that takes place in an already structured space of significations, privileges and practice (Carter, Clegg, \& Kornberger, 2008). For Bourdieu (1977), failure to recognise the notion of time is to abolish strategy. Brent Davies and colleagues have regularly acknowledged the impact of timing on strategy. In Davies and Davies (2005) they highlight the need to 
determine effective intervention points, or simply, doing the right things at the right time. Davies expands this by calling on the work of others and his own previous research to suggest that knowing what not to do at a given time (Kaplan \& Norton, 2001) and when to abandon a course of action as equally important. As such, strategic timing has two elements: first is the recognition of current actions and inactions on the basis of historical events; and secondly, the positioning of current actions and inactions in relation to future events. While it is difficult if not impossible to predict the future, the good strategist is able to interpret the current situation and make moves based on an intimate knowledge of what the moves of others will be. In effect, the strategist is anticipatory, producing an effect in anticipation of its cause. In doing so, the strategist shapes the future, or at least a history not yet written, rather than merely reacting to the present. Strategists have a combination of knowledge and understanding built from experience (the unconscious) and explicitly developed tools or problem solving techniques (conscious). Not an entirely controversial claim, but one which challenges conventional ways of knowing about strategy in education.

\section{Conclusion}

Principals are nowadays confronted with problems that are more complex and disturbing than would have been the case several decades ago (Maxcy, 1993), but while new discourses on educational leadership contain many varied and sometimes incompatible voices, there seems to be a common thread of moving away from a linear, technological approach in which leadership is conceived as a means to bring about predetermined ends. Informed by a continuing research program on strategy in education, this paper argues that in order to understand strategic leadership practice, leaders thinking and behaviour as well as their situation need to be considered 
together in an integrated framework. Understanding the what of strategic leadership is essential, but without a rich understanding of how and why leaders do and think what they do, it is difficult to help other school leaders to think about and improve practice.

In seeking to go beyond what is already known in the field, the ideas proposed in this paper are meant to stimulate debate and further inquiry. They are intended to provide a new platform for theory and methodological developments. The positioning of strategy within a wider social space, poses key methodological questions for scholars and critical key points of reflection for practitioners. For scholars, it is no longer appropriate to study strategy in isolation. This proposition is clearly designed to be provocative, although, it is also meant to be an optimistic perspective and not just a radical rejection of conventional scholarship. It challenges the uncritical acceptance of market and economic based models of strategic management, and in doing so, bypasses approaches to scholarship on strategy in education which populate most educational leadership journals and books. In conclusion, the theory development process undertaken in producing this paper has been evolutionary. The route taken has not been about filing voids in the literature, but through an engagement with problems in the world. Bacharach (1989) suggests that for theory building there is a fine line between satisfying the criteria of the internal logic of theory and achieving a creative contribution. It is hoped that this paper walks that line carefully.

\section{References}

Bacharach, S. B. 1989. Organizational theories: some criteria for evaluation. Academy of Management Review 14 no. 4: 496-515.

Ball, S.J. 1997. Good school/bad school: paradox and fabrication. British Journal of Sociology of Education 18 no. 3: 317-336.

Ball, S.J. 2003. The teacher's soul and the terrors of performativity. Journal of Education Policy 18 no. 2: 215-228. 
Bell, L. 2002. Strategic planning and school management: full of sound and fury, signifying nothing? Journal of Educational Administration 40 no. 5: 407-424.

Bourdieu, P. 1977. Outline of a theory of practice. Cambridge, UK: University Press.

Bourdieu, P. 1988. Vive la crise! For heterodoxy in social science. Theory and Society 17 no. 5: 773-787.

Bourdieu, P. (1989), “Social space and symbolic power”, Sociological Theory, Vol. 7 No. 1, pp. 14-25.

Bourdieu, P. 1998. Practical reason: on the theory of action. Cambridge, UK: Polity Press.

Bush, T. 2007. Theory and research in educational leadership and management. Educational Management Administration \& Leadership 35 no. 1: 5-8.

Carter, C., Clegg, S. R., \& Kornberger, M. 2008. Strategy as practice? Strategic Organization 6 no. 1: 83-99.

Cuckle, P., \& Broadhead, P. 2003. Developments in development planning in English primary schools: 1994-2001. School Leadership and Management 23 no. 2: 229-240.

Davies, B., \& Davies, B. J. 2005. Strategic leadership. In The essentials of school leadership, ed. B. Davies, 13-36. London: Paul Chapman.

Davies, B. J., \& Davies, B. 2006. Developing a model for strategic leadership in schools. Educational Management Administration \& Leadership 34 no. 1: 121-139.

Deming, W. E. 1982. Out of the crisis. Cambridge, MA: MIT Press.

Dimmock, C., \& Walker, A. 2004. A new approach to strategic leadership: learningcentredness, connectivity and cultural context in school design. School Leadership and Management 24 no. 1: 39-56.

Eacott, S. 2009. Strategic leadership and public school principals: a study in New South Wales Australia. Saarbrücken, Germany: Verlag Dr Muller.

English, F.W. 2003. The postmodern challenge to the practice of educational administration. Springfield, IL: Charles C Thomas Publisher Ltd.

Fay, B. 1994. General laws and explaining human behaviour. In Readings in the philosophy of social science, ed. M. Martin \& L. C. McIntyre, 54-110. Cambridge, MA: MIT Press.

Gunter, H. 2004. Labels and labelling in the field of educational leadership. Discourse: Studies in the Cultural Politics of Education 25 no. 1: 21-41.

Kaplan, R. S., \& Norton, D. P. 2001. The strategy-focused organization. Boston, MA: Harvard Business School Press.

Lamaison, P., \& Bourdieu, P. 1986. From rules to strategies: an interview with Pierre Bourdieu. Cultural Anthropology 1 no. 1: 110-120.

Lingard, B., \& Christie, P. 2003. Leading theory: Bourdieu and the field of educational leadership. International Journal of Leadership in Education 6 no. 4: 317-333.

Lingard, B., Hayes, D., Mills, M., \& Christie, P. 2003. Leading learning: making hope practical in schools. Buckingham, UK: Open University Press.

Lingard, B., Rawolle, S., \& Taylor, S. 2005. Globalizing policy sociology in education: working with Bourdieu. Journal of Education Policy 20 no. 6: 759777.

Maxcy, S. J. 1993. Introduction. In Postmodern school leadership: meeting the crisis in educational administration, ed. S.J. Maxcy, 1-13. Wesport, CT: Praeger.

Ranson, S. 2003. Public accountability in the age of neo-liberal governance. Journal of Education Policy 18 no. 5: 459-480. 
Strauss, A. \& Corbin, J. 1998. Basics of qualitative research: techniques and procedures for developing grounded theory. Thousand Oaks, CA: SAGE.

Taylor, F. W. 1911. The principles of scientific management. New Work, NY: W.W. Norton.

Vavrus, F., \& Bartlett, L. 2006. Comparatively knowing: making a case for the vertical case study. Current Issues in Comparative Education 8 no. 2: 95-103.

\section{Author bionote:}

Scott Eacott is a lecturer in Educational Leadership, Management and Administration at the University of Newcastle, Australia. His current major research areas are strategy in education and the teaching of educational leadership in universities. He teaches a range of educational leadership courses at both the post/under-graduate levels and supervises higher degree researchers. 